\title{
Advanced diagnostic endoscopy for colorectal tumors: Challenges that need to be solved in the years to come
}

다 (i)

\author{
Authors \\ Thierry Ponchon ${ }^{1}$, Cesare Hassan ${ }^{2}$ \\ Institutions \\ 1 Digestive Diseases Department, Lyon University \\ Hospital, France \\ 2 Gastroenterology Unit, Nuovo Regina Margherita \\ Hospital, Rome, Italy \\ Bibliography \\ Endosc Int Open 2021; 09: E1865-E1867 \\ DOI 10.1055/a-1552-3346 \\ ISSN 2364-3722 \\ (c) 2021. The Author(s).
}

\author{
This is an open access article published by Thieme under the terms of the Creative \\ Commons Attribution-NonDerivative-NonCommercial License, permitting copying \\ and reproduction so long as the original work is given appropriate credit. Contents \\ may not be used for commercial purposes, or adapted, remixed, transformed or \\ built upon. (https://creativecommons.org/licenses/by-nc-nd/4.0/) \\ Georg Thieme Verlag KG, Rüdigerstraße 14, \\ 70469 Stuttgart, Germany \\ Corresponding author \\ Thierry Ponchon, Edouard Herriot Hospital - \\ Hepatogastroenterology, Place Arsonval, Lyon 69003, France \\ Fax: +33472110147 \\ thierry.ponchon@chu-lyon.fr
}

The purpose of this editorial is not to detail all the technical aspects of advanced diagnostic endoscopy for colorectal tumors but to focus on some of the issues raised by diagnostic endoscopy, with which impressive progress has been made in recent years, at least regarding its use for therapeutic colonoscopy.

\section{Challenges regarding detection}

\section{Electronic chromoendoscopy}

The most recent literature shows that techniques using electronic chromoendoscopy (EC), particularly from the latest generation, improve adenoma detection rates by enhancing the contrast between the lesion and the surrounding mucosa [1-4]. But these techniques, if they are simple to implement, are not widely used, especially in Europe, and there are no recommendations that impose these techniques first-line for those at average-risk of colorectal cancer (CRC). For example [5], The European Society of Gastrointestinal Endoscopy (ESGE) suggests that "virtual chromoendoscopy can be used to increase the endoscopist's adenoma detection rate (ADR). Their routine use must be balanced against costs....". Why not "has to be used" instead of "can be used"? Possible challenges preventing its use, such as lack of adequate training, user-experience, and additional withdrawal time, should be addressed. More endoscopist-friendly EC alternatives may be game-changing. By mixing the blue component with red and green components, new lights mimicking the bright appearence of the usual white-light have been developed, while preserving the same efficacy as traditional EC. The challenge is whether and when these tech- niques will be recommended as a first line and will replace white light imaging (WLI) for detection in the colon.

\section{Artificial intelligence}

The most recent publications show that artificial intelligence (Al) techniques improve the adenoma detection rate (ADR). All published trials comparing Al to WLI reported an effect on ADR in the Al groups and a recent meta-analysis [6] concluded that ADR with $\mathrm{Al}$ is much higher than ADR with WLI. The first challenge concerning $\mathrm{Al}$ is to continue to evaluate Al. We need more data on the rate of false-positive results, more data for non-polypoid lesions and on cost-effectiveness due to effect of withdrawal time, additional costs for polypectomy and for surveillance. In addition, the issue of de-skilling, especially for trainees, must be considered. Will Al users be able to achieve adequate standards when $\mathrm{Al}$ is not available?

The second challenge is whether the promising data apply to all Al algorithms, which are numerous. In other words, will there be an evaluation and labeling of the different Al techniques? A PIVI (Preservation and Incorporation of Valuable endoscopic Innovations) statement, such as the one recommended by the American Society of Gastrointestinal Endoscopy, could be useful for Al "to avoid widespread use before clinical studies documenting effectiveness have been performed." Technical comparisons across different systems with a rigorous ground-truth may be expected to prevent excessive variability in Al-assisted detection. This is critical when implementing $\mathrm{Al}$ in population-based programs in which a consistent standard is especially required. 
The third challenge is to better evaluate whether Al can be combined adequately with electronic chromoendoscopy techniques. That is not certain, but possible. Will the gold standard be a combination of Al and electronic chromoendoscopy or will the latter be made obsolete by AI?

The fourth challenge is medico-legal and consists of determining precisely what the level of responsibility is related to Al. So far, Al has been presented as assisting the operator and the operator as responsible for detection, i.e., Al is a low-risk medical device. But a day will come when, in the event of a medico-legal case brought after a lesion has been missed that the respective responsibilities of the operator and the Al will be clarified. This also addresses the need to document Al output at each examination. Should all the Al triggers be saved, only those relevant from a clinical perspective, or neither of them?

The fifth challenge will be commercial. How can any hospital equip itself with so many different systems, particularly if the systems evolve frequently? Maybe the best business model will be to lease different systems that can be upgraded regularly.

\section{Devices to explore the colonic mucosa behind the folds}

Currently, distal attachment devices, especially Endocuff, have been shown to be effective in detecting lesions behind the folds in areas that are difficult to explore, and in increasing ADRs $[6,7]$. As for electronic chromoendoscopy, the first challenge for scientific societies such as ESGE is to decide if the use of these devices (and which ones?) is only suggested ("can be used") or strictly recommended ("has to be used"). Possible barriers may prevent add-on implementation. These devices usually represent an additional cost per colonoscopy that is currently not reimbursed by several health systems. Despite their overall efficacy, there is variability in the intrinsic mechanism of adds-on, i. e. cap vs. cuffs, generating uncertainty about the best way to flatten the fold. The educational context seems relevant. The use of the cap is reported in a substantial proportion of screening colonoscopies in Japanese series, while this approach is missing from Western-based series. The second challenge does once again concern $\mathrm{Al}$ : $\mathrm{Al}$ will help to determine whether the exploration of the colonic mucosa has been complete or not and whether unexplored areas persist. The challenge will then be to combine attachment devices and Al.

\section{Challenges regarding characterization (optical diagnosis)}

\section{Limiting the number of classifications}

Indeed, Western endoscopists tend to analyze fewer details than Japanese endoscopists and to use fewer classifications. This is primarily related to the reluctance of Western endoscopists to use optical magnification, which in contrast is on the standard for Japanese endoscopists, and Japanese-driven classifications. Therefore, in order for a Western endoscopist to adhere to the classifications, the number of them should be limited. There has already been an attempt to limit the number of classifications by establishing international classifications, such as the NBI International colorectal endoscopic classification (NICE) or Japan NBI Expert Team (JNET). In fact, the problem is that the fewer classifications there are, the more complex they should be to cover all situations. Finding a balance between the number of classifications and their respective complexity is a difficult challenge. An additional chalenge is Al development in this arena. Will classifications adhere to the histologically-mimicking Al-output, such as neoplastic vs. non-neoplastic or adenoma vs. non-adenoma?

\section{Comparing different endoscopes from different companies}

Indeed, it is necessary to avoid having a classification for each endoscope company (NICE, BASIC, SIMPLE,...). Conversely, after demonstration, scientific societies should be able to indicate that a particular technology is better and more adapted than another technology. Currently, there is a certain policy of juxtaposition of technologies and non-aggression between the different endoscope companies. It would be preferable to move towards a policy of homogenization but to maintain a certain degree of competition [7]. A difficult challenge politically speaking!

\section{Distinguishing between hyperplastic polyps and adenomas (NICE type 1 vs type 2)}

Distinguishing these two types of polyps is the basis of the discard policy (to resect but not perform histopathology). This policy has a rationale: it reduces costs and is feasible and safe. But the first part of the challenge is whether it concerns diminutive polyps $(<5 \mathrm{~mm})$ or small polyps $(6-10 \mathrm{~mm})$. The second part is whether the challenge should be restricted to the "leave-in-situ" strategy for rectosigmoid diminutive hyperplastic polyps or extended to the "resect-and-discard" for adenomatous or more proximal yeperplastic lesions. The former is easier but clinically less relevant, if at all, while the second may pose additional challenges, such as reimbursement for optical diagnosis and legal and financial issues, as histology is mandatory for reimbursement in some health systems, and general reluctance by patient population. Part of the challenge is for scientific societies like the ESGE to promote or not promote this policy. This is not the case at the moment because routinely the results are not as good as with the experts and because there is the problem of sessile serrated lesions (SSLs) that behave like adenomatous lesions but look like hyperplastic lesions. Despite various attempts, incorporating SSLs into current classifications remains difficult. To date, ESGE states that it is possible to discard polyps, as long as photodocumentation and certified training are organized, but it is not recommended. With regard to photodocumentation, it means having defined quality criteria for pictures and having defined quality criteria for the preservation and storage of documents (how long? and on what medium?). For certified training, this means having a certification program in place. This is not simple and is not yet the case for ESGE. By offering very high accuracy values, AI may further push these challenges. Will health systems and patients be happy to rely on an $\mathrm{Al}$-driven diagnosis? Will an endoscopist 
with no skills in optical diagnosis be ready to passively accept AI output? Will scientific societies like ESGE be ready to rely on AIdriven certified diagnosis?

\section{Improving detection of a carcinomatous component within an adenoma and to better predict the level of parietal invasion (e.g., type $2 \mathrm{~A}$ vs type $2 \mathrm{~B}$ vs type 3 of the JNET classification)}

With the development of endoscopic submucosal invasion, the question arises in all countries, including Western countries. But unlike NICE 1 vs NICE 2, the challenge is to analyze a continuous variable: from regular to irregular, there is no clear limit. Even in Japan, the study results are not perfect. The level of expertise is less in Europe, so the challenge is to set up quality training with evaluation. This may have annoying consequences such as excessive referral to surgery for benign lesions. Moreover, the situation is complicated by the fact that Europeans do not use crystal violet with optical magnification for pit pattern evaluation, which is very useful and widely used in Japan. On one hand, Europeans tend to make little use of dyes although they have in their operating rooms Lugol, indigo carmine and acetic acid and they will not accept so easily a fourth dye. On the other hand, crystal violet is considered potentially toxic and carcinogenic in Europe. Endocytoscopy also appears to be a very interesting tool to better diagnose a carcinomatous area within an adenoma [8] but the routine use of endocystoscopy will be limited by three factors : (1) the need to apply methylene blue, another potentially carcinogenic dye, prior endocystoscopy; (2) the duration of a complete analysis of the polyp surface; and (3) the cost of the system. A cost-effectiveness analysis is mandatory before any routine use of endocystoscopy. Al linked to image-enhanced endoscopy is likely to be the best option to solve challenges 3 and 4 in Europe in the near future.

\section{Conclusions}

To conclude, diagnostic colonoscopy has made impressive progress in recent years, thanks to implementation of quality criteria and to the availability of new technology. But of course, the arrival of new technology gives rise to major challenges, which must be quickly resolved through rigorous evaluation and well- balanced statements by scientific societies. This should be done before $\mathrm{Al}$ implementation. To bypass all of these pre-Al challenges, while missing the benefit of them, may be the worst start for Al implementation in diagnostic colonoscopy!

\section{Competing interests}

Olympus (advisory board, lecture fees, research funding) Fujifilm (research funding)

\section{References}

[1] Atkinson NSS, Ket S, Bassett P et al. Narrow-Band Imaging for detection of neoplasia at colonoscopy: A meta-analysis of data from individual patients in randomized rontrolled trials. Gastroenterology 2019; 157: 462-471

[2] Lovász BD, Milán Szalai M, Oczella L et al. Improved adenoma detection with linked color imaging technology compared to white-light colonoscopy. Scand J Gastroenterol 2020; 55: 877-883

[3] Kidambi TD, Terdiman JP, El-Nachef $\mathrm{N}$ et al. Effect of I-scan electronic chromoendoscopy on detection of adenomas during colonoscopy. Clin Gastroenterol Hepatol 2019; 17: 701-708

[4] Ikematsu I, Sakamoto T, Togashi K et al. Detectability of colorectal neoplastic lesions using a novel endoscopic system with blue laser imaging: a multicenter randomized controlled trial. Gastrointest Endosc 2017; 86: 386-394

[5] Bisschops R, East JE, Hassan C et al. Advanced imaging for detection and differentiation of colorectal neoplasia: European Society of Gastrointestinal Endoscopy (ESGE) Guideline - Update 2019. Endoscopy 2019; 51: 1155-1179

[6] Patel HK, Chandrasekar VT, Srinivasan S et al. Second-generation distal attachment cuff improves adenoma detection rate: meta-analysis of randomized controlled trials. Gastrointest Endosc 2021; 93: 544553

[7] Leung WK, Guo CG, Ko MKL et al. Linked color imaging versus narrowband imaging for colorectal polyp detection: a prospective randomized tandem colonoscopy study. Gastrointest Endosc 2020; 91: 104112

[8] Mori Y, Kudo SE, Misawa M et al. Artificial intelligence-assisted colonic endocystoscopy for cancer recognition: a multicenter study. Endosc Int Open 2021; 7: E1004-E1011 